\title{
DE LO IDEAL A LO REAL: SENTENCIA DE LA CIDH SOBRE EL ENCARCELAMIENTO PREVENTIVO
}

\section{FROM THE IDEAL TO THE REAL: THE IACHR RULING ON PRETRIAL DETENTION}

Juan Cruz Chapuy ${ }^{1}$

DOI: https://doi.org/10.37767/2591-3476(2021)09

\section{Comentario a}

Corte Interamericana de Derechos Humanos. Caso Montesinos Mejía vs. Ecuador. Sentencia del 27 de enero de 2020

\section{Disponible en}

https://bit.ly/38olBKR

\section{RESUMEN:}

El 27 de enero de 2020, la Corte Interamericana de Derechos Humanos declaró responsable al Estado ecuatoriano por la violación de derechos y garantías regulados en la Convención Americana de Derechos Humanos contra el ciudadano Mario Alfonso Montesinos Mejía. En consecuencia, la Corte dispuso una serie de medidas a cumplir por el Estado responsable de dichas vulneraciones, resaltando la supremacía del ordenamiento internacional sobre el doméstico. La detención ilegal de Montesinos Mejía se prolongó desde 1992 hasta 1998.

\section{ABSTRACT}

On January 27, 2020, the Inter-American Court of Human Rights declared the Ecuadorian State responsible for the violation of rights and guarantees regulated in the American Convention on Human Rights against citizen Mario Alfonso Montesinos Mejía. Consequently, the Court ordered a series of measures to be complied with by the State responsible for such violations, highlighting the supremacy of international law over domestic law. The illegal detention of Montesinos Mejía lasted from 1992 to 1998.

1 Abogado, Mediador (Universidad Nacional de Córdoba). Litigante del foro penal en la provincia de Mendoza. Miembro de la Asociación pensamiento Penal y de Victimas Por la Paz. E-mail: chapuy.jc@gmail.com. ORCID iD: https://orcid.org/0000-0003-4144-6554. 
PALABRAS CLAVE: convención americana- prisión preventiva- corte interamericana de derechos humanos- tribunal constitucional de garantías- plazo razonable procesos penales.

KEY WORDS: American Convention - Pretrial detention - Inter-American Court of Human Rights - Constitutional Court of Guarantees - Reasonable time limit for criminal proceedings

\section{Introducción}

El siguiente trabajo es un comentario a la sentencia dictada por la Corte Interamericana de Derechos Humanos (en adelante, la Corte o el Tribunal) en la cual consideró al Estado de Ecuador (en adelante, el Estado o Ecuador) responsable de la violación de los derechos a la libertad personal, a la presunción de inocencia y a la protección judicial, como así también responsable de la violación de las obligaciones de proteger y garantizar el derecho a la integridad personal y a las garantías judiciales en contra del Sr. Montesinos Mejía, previstos en la Convención Americana de Derechos Humanos (en adelante, la Convención). A su vez, por unanimidad, determinó su responsabilidad por vulnerar los artículos 1, 6 y 8 de la Convención Interamericana para Prevenir y Sancionar la Tortura.

\section{Reseña del caso}

Mario Alfonso Montesinos Mejía fue detenido el 21 de junio de 1992 mientras se encontraba conduciendo su automóvil en la ciudad de Quito, Ecuador, junto a su esposa y su hermana. Durante la detención, la policía local le habría indicado a Mario Alfonso que tenían una orden de allanamiento para ingresar a su domicilio emitida por el comisario primero del Cantón de Quito. Luego de detenerlo, los agentes policiales lo llevaron a su domicilio y lo tuvieron retenido en el vehículo policial por aproximadamente dos horas, mientras se realizaba el allanamiento, que arrojó como resultado el decomiso de distintos armamentos. Tanto para su detención como para el allanamiento, no existe en el expediente orden judicial alguna que autorice dichas medidas.

Es dable destacar que la detención de Montesinos tuvo lugar en el marco de la lucha contra el narcotráfico en Ecuador, puntualmente con el Operativo "El Ciclón", llevado a cabo por el Servicio de Inteligencia Antidroga de la Policía Nacional cuya finalidad fue desarticular una organización dedicada al narcotráfico.

Producto de su detención, su declaración (la cual se adelanta que fue obtenida mediante coacción, por lo que carece de validez) y lo decomisado en el allanamiento a su morada, se iniciaron tres procesos penales en su contra, a saber: enriquecimiento ilícito; conversión y transferencia de bienes; y testaferrismo, todos ellos conforme la ley penal ecuatoriana.

\section{Procedimiento ante la Corte}

El presente caso se inicia con una petición presentada ante la Comisión Interamericana de Derechos Humanos (en adelante, la Comisión) por el abogado de Montesinos, Alejandro Ponce Villacís, en contra de Ecuador el 20 de agosto de 1996. Posteriormente, la Comisión emite su Informe de Admisibilidad y Fondo, en octubre de 2017, notificando al Estado ecuatoriano el 18 de enero de 2018.

El 18 de abril de 2018, la Comisión sometió el caso a la Corte respecto de los hechos y las 
violaciones de derechos humanos que constan en el Informe de Admisibilidad y Fondo.

En cuanto a la competencia de la Corte para entender y resolver el presente caso, vale recordar que, desde el 28 de diciembre de 1977, el Estado de Ecuador es parte de la Convención Americana, y reconoció la competencia contenciosa de la Corte en julio de 1984. En suma, la misma Constitución ecuatoriana reconoce esta estructura de derecho en cuanto al ordenamiento jurídico supranacional.

Cuatro fueron las excepciones preliminares que el Estado formuló en su escrito de contestación, a saber: a) la incompetencia de la Corte en razón del tiempo; b) la falta de agotamiento de recursos internos; c) la incompetencia de la Corte en razón de la materia y la utilización del Sistema Interamericano de Derechos Humanos como una cuarta instancia; y d) el control de legalidad de las actuaciones de la Comisión y la vulneración del derecho de defensa del Estado.

Todas las excepciones presentadas fueron consideradas y rechazadas por la Corte que fundó minuciosamente las razones por las cuales no tuvieron lugar, para posteriormente avocarse al estudio del fondo del asunto.

Resueltas las excepciones, reconocida la competencia y admitida la prueba, la Corte se adentró en el análisis de los derechos vulnerados en el caso de marras.

\section{Derechos vulnerados}

La Corte analizó los hechos expuestos por la Comisión y el Representante de la presunta víctima (en adelante el Representante), es decir la alegada detención arbitraria e ilegal que sufrió Montesinos, los alegados tratos crueles, inhumanos, degradantes y tortura, como también la falta de garantías judiciales en los procesos penales seguidos en su contra. El Estado con sus fundamentos intentó desligarse de responsabilidad internacional poniendo de relieve su celoso cumplimiento del ordenamiento jurídico interno.

En esta inteligencia, la Corte desarrolló su análisis jurídico en relación con las supuestas violaciones en el siguiente orden: a) los derechos a la libertad personal, a la presunción de inocencia y a la igualdad ante la ley; b) el derecho a la integridad personal y la obligación de investigar delitos de tortura; y c) los derechos y garantías judiciales y la protección judicial.

\section{Derecho a la libertad personal y presunción de inocencia}

La Corte realizó un análisis separado de la privación de libertad sufrida por Mario Alfonso, centrándose en su primera detención (21 de junio de 1992), el dictado de la prisión preventiva y su mantenimiento durante los años posteriores, hasta recuperar su libertad.

En relación con su primera detención, no existe en el expediente constancia alguna de una orden de detención emanada por autoridad competente en su contra, como tampoco de una orden de allanamiento que respaldase lo acontecido luego de su detención.

Tanto la Constitución vigente al momento del hecho como el Código de Procedimiento Penal de Ecuador, exigían una orden judicial que garantizara la procedencia de la detención. Dicha orden de detención sería materializada mediante una Boleta que contuviera los motivos de la privación de libertad, el lugar y fecha en la que fuera expedida y la firma 
del juez competente. La excepción a esta norma era que la detención se produjera cuando la persona estuviese cometiendo un delito flagrante.

Ante la inexistencia de dicha orden de detención y la ausencia de flagrancia, resulta evidente que la aprehensión de Montesinos fue ilegal y, por tanto, violatoria de la norma ecuatoriana y, consecuentemente, violatoria del artículo 7.2 de la Convención Americana, que reza lo siguiente: Nadie puede ser privado de su libertad física, salvo por las causas y en las condiciones fijadas de antemano por las Constituciones Políticas de los Estados Partes o por las leyes dictadas conforme a ellas.

Respecto del dictado de prisión preventiva en contra de Montesinos, la Corte fue categórica al definir como ilegal la medida cautelar impuesta. Resulta oportuno destacar que estamos hablando de la medida cautelar más gravosa y excepcional que existe en el orden jurídico supranacional, la cual requiere para su dictado el cumplimiento de una serie de requisitos a fin de que no se torne arbitraria. Como instruye la Corte, dentro de los requisitos para el dictado de la prisión preventiva señalamos la existencia de indicios suficientes que permitan suponer razonablemente que un hecho ocurrió y que la persona sometida a proceso pudo haber participado en él. También, la existencia de elementos de concretos de juicio que acrediten que la persona imputada por un delito necesariamente entorpecerá la investigación penal en su contra o intentará eludir el accionar de la justicia dándose a la fuga. En cualquier caso, siempre deberá estar adecuadamente fundada. Ninguno de estos requisitos fue presentado al momento del dictado de la prisión preventiva de Montesinos.

Por suyo, la Corte advierte que no existe en el expediente razón alguna, motivación o justificación formal que permita ordenar la prisión preventiva. Ni siquiera en los autos cabeza de proceso de noviembre de 1992 se encontraron razones para mantener a la presunta víctima bajo prisión preventiva, como tampoco existieron razones para su detención inicial.

No son pocos los fallos en donde la Corte sostiene que las características personales del supuesto autor, como la gravedad del delito, no son óbice por sí mismo para justificar el dictado de la prisión preventiva, citando a modo de ejemplo lo resuelto por la Corte en el caso López Álvarez vs. Honduras (cfr. párr. 69) o el caso Bayarri vs. Argentina (cfr. Excepción Preliminar, Fondo, Reparaciones y Costas).

Mención particular merece la situación de las personas privadas de su libertad sin sentencia firme emanada por autoridad competente en su contra. Un estudio elaborado por el Centro de Estudios de Justicia de las Américas (CEJA) nos ofrece una estadística que resulta de gran utilidad para comprender la dimensión del problema del encarcelamiento preventivo: en la República de Ecuador, para 1992, el porcentaje promedio de personas presas sin la existencia de condena llegaba al 64 por ciento de la población penitenciaria, y para 1999 ascendía al 69 por ciento, lo que resulta un número absolutamente desalentador ya que significa que la mayor parte de la población carcelaria se encontraba privada de su libertad preventivamente, sin alcanzar el grado convictivo que se requiere, generando un alto índice de inseguridad jurídica en nuestras sociedades (Carranza, 2001).

La Corte no solo entendió que el dictado de la prisión preventiva se desarrolló de manera arbitraria, sino que el Estado tampoco realizó su revisión de oficio, lo que vulnera los 
artículos 7.1 y 7.3 de la Convención Americana.

Respecto de la razonabilidad del plazo de la prisión preventiva, diremos que para 1996 Montesinos Mejía llevaba más de cuatro años privado de su libertad. Frente a la falta de respuesta judicial, presentó una petición de habeas corpus

Sin embargo, esta petición fue declarada improcedente ${ }^{2}$. Frente a esta situacion, el abogado representante de Montesinos apeló la decisión denegatoria ante el Tribunal Constitucional de Garantías. En octubre de 1996, dicho Tribunal Constitucional de Garantías concedió el habeas corpus y ordenó la inmediata libertad de Montesinos Mejía exponiendo que existió un retraso judicial injustificado por parte de los jueces para emitir sentencia.

El 14 de abril de 1998, Montesinos interpuso un nuevo habeas corpus, toda vez que lo resuelto en función del anterior no fue cumplido. Es decir, no se materializó la libertad inmediata tal como lo había resuelto el Tribunal Constitucional de Garantías. Recién el 8 de agosto de 1998 el Tribunal Constitucional determinó la inmediata libertad de Montesinos Mejía, considerando irrazonable el tiempo de prisión preventiva.

Si bien la Corte no tiene constancia de la fecha exacta en la cual Montesinos fue puesto en libertad, fue en 1998, es decir, seis años después de su detención primaria. Es por esta razón que la Corte concluyó que el periodo de seis años y dos meses durante los cuales Mario Alfonso estuvo en prisión preventiva resultó absolutamente irrazonable, excesivo y violatorio de los artículos 7.1 y 7.5 de la Convención.

Sobre la presunción de inocencia, el artículo 8.2 de la Convención establece que "toda persona inculpada tiene derecho a que se presuma su inocencia mientras no se establezca legalmente su culpabilidad". Al respecto, la Corte determinó que, al carecer de fundamentación y motivación, la prisión preventiva dictada fue arbitraria. En consecuencia, todo el extenso periodo de privación de libertad sufrido fue equivalente a una verdadera pena anticipada, lo que colisiona o entra en franco conflicto con el principio de inocencia. De haberse respetado desde un principio, no debería haber sido privado de su libertad jamás. Lamentablemente, este avasallo a la presunción de inocencia tiene lugar cotidianamente en los ordenamientos jurídicos locales latinoamericanos.

En este punto, la Corte concluye que el Estado violó los derechos a la libertad personal, a las garantías judiciales y la protección judicial, establecidos en los artículos 7.1, 7.2, 7.4, 7.5, 8.2 y 24 de la Convención Americana sobre Derechos Humanos, en relación con el artículo 1.1 del Tratado, así como los artículos 7.1, 7.3 y 7.6 del mismo instrumento, en relación con los artículos 1.1 y 2.

\section{Derecho a la integridad personal y la obligación de investigar denuncias de tor- tura}

Montesinos Mejía manifestó haber sido amenazado y describió cómo cursó su detención en una celda de 11 metros cuadrados con 13 personas más. Sostuvo que fue golpeado por agentes estatales y dijo haber estado incomunicado. Tanto la Comisión como el Representante expresaron que el Estado no inició ninguna investigación respecto a la de-

2 Resolución 182-96-CP expedida por el Tribunal de Garantías Constitucionales dentro del marco del caso Nro. 45/96-TC (expediente de prueba, folio 46). 
nuncia realizada por Montesinos en su primer habeas corpus, relativo al sufrimiento de la violación de su integridad personal. En su derecho, el Estado respondió que el ordenamiento jurídico ecuatoriano vigente al momento de los hechos brindaba protección a la garantía de integridad personal y prohibía los tratos crueles, inhumanos o degradantes, destacando que no existió vulneración al artículo 5.2, ya que los datos vertidos por el Representante no resultaban concretos ni específicos.

A los fines de poder determinar la existencia de lo manifestado por la Comisión y el Representante, la Corte cuenta con una herramienta de trascendental importancia: el fallo Suárez Rosero. Al respecto, la Corte observa que efectivamente Montesinos Mejía estuvo detenido junto a Rafael Iván Suárez Rosero, tanto en el Penal García Moreno como también en el Ilamado Regimiento de Quito. Incluso en su declaración, Suárez Rosero reconoció haber recibido golpizas junto a Montesinos Mejía ${ }^{3}$. Resulta oportuno citar lo que la Corte pudo advertir en el caso Suárez Rosero en lo que hace a los actos de tortura, tratos crueles, inhumanos y degradantes, cuando expresó: La sola constatación de que la víctima fue privada durante 36 días de toda comunicación con el mundo exterior y particularmente con su familia, le permite a la Corte concluir que el señor Suárez Rosero fue sometido a tratos crueles, inhumanos y degradantes, más aún cuando ha quedado demostrado que esta incomunicación fue arbitraria y realizada en contravención de la normativa interna del Ecuador. La víctima señaló ante la Corte los sufrimientos que le produjo verse impedido de la posibilidad de buscar un abogado y no poder ver o comunicarse con su familia. Agregó que, durante su incomunicación, fue mantenido en una celda húmeda y subterránea de aproximadamente 15 metros cuadrados con otros 16 reclusos, sin condiciones necesarias de higiene y se vio obligado a dormir sobre hojas de periódico y los golpes y amenazas a los que fue sometido durante su detención. Todos estos hechos confieren al tratamiento a que fue sometido el señor Suárez Rosero la característica de cruel, inhumano y degradante. Por las anteriores consideraciones, la Corte declara que el Estado violó el artículo 5.2 de la Convención Americana ${ }^{4}$.

En esta inteligencia, la Corte concluyó que el Estado incumplió con su obligación internacional de respetar y garantizar el Derecho a la Integridad Personal, vulnerando así los artículos 5.1 y 5.2 de la Convención. Asimismo, también encontró responsable al Estado ecuatoriano de la falta de investigación de la denuncia de tortura y malos tratos, lo que resulta violatorio de los artículos 1, 6 y 8 de la Convención Interamericana para Prevenir y Sancionar la Tortura, en perjuicio de Mario Montesinos.

\section{Derecho a las garantías judiciales}

El derecho humano a gozar de las debidas garantías judiciales dentro del proceso penal encuentra asidero jurídico en el artículo 8 de la Convención Americana. Tanto la Comisión como el Representante coincidieron en aseverar que el Estado de Ecuador vulneró: a) la regla de exclusión de pruebas obtenidas bajo coacción; b) el derecho de defensa; c) el principio de presunción de inocencia; y d) la razonabilidad en la duración de los procesas penales.

Por su parte, el Estado negó que se hubieran violado las garantías judiciales del artículo 8 de la Convención Americana. En primer lugar, en relación con la duración razonable del proceso penal, el Estado le atribuyó la responsabilidad a Montesinos Mejía, quien, con los distintos recursos y actuaciones presentadas, fue dilatando el proceso. Recordó que

3 Declaración rendida ante fedatario público por Rafael Iván Suárez Rosero el 7 de agosto de 2019 (expediente de pruebas, folios 2895 y 2896).

4 Caso Suárez Rosero vs. Ecuador, párr. 91. 
Montesinos fue juzgado por jueces competentes. Como segundo punto, el Estado destacó que la normativa procesal ecuatoriana ha garantizado la presunción de inocencia, ejemplificando con los procesos penales que sobreseyeron a Montesinos. Por último, rechazó que se hubiera negado el derecho a una defensa técnica, asegurando que Montesinos siempre contó con defensa técnica y patrocinio jurídico.

La Corte, tal como lo señaló en el caso Claude Reyes y otros vs. Chile, estableció que, de acuerdo con lo dispuesto en el artículo 8.1 de la Convención, en la determinación de los derechos y obligaciones de las personas, de orden penal, civil, laboral, fiscal o de cualquier otro carácter, se deben observar "las debidas garantías" que aseguren, según el procedimiento de que se trate, el derecho al debido proceso. El incumplimiento de una de esas garantías conlleva una violación de dicha disposición.

Centrándose en el plazo razonable de duración del proceso penal, la Corte realizó el mismo proceso cognitivo que en el caso Anzualdo Castro vs. Perú y el caso Jenkins vs. Argentina, y consideró cuatro elementos a fin de determinar si existió o no vulneración a la garantía de plazo razonable; primero, la complejidad del asunto; segundo, la actividad procesal del imputado; tercero, la conducta de las autoridades judiciales; y por último, la afectación generada en la situación jurídica de la persona involucrada en el proceso.

Sobre los delitos de enriquecimiento ilícito y conversión y transferencia de bienes, la Corte entendió que no existió ninguna complejidad que justificara los seis años de demora en su finalización. Con relación al delito de testaferrismo, observó que el caudal probatorio que llevó a la condena de Montesinos, en 2008, no varió desde 1992, año en el cual fue detenido, y que no existían elementos adicionales en el proceso que ofrecieran una complejidad tal que justificase una demora de 18 años en su tramitación. En consecuencia, concluyó que el Estado de Ecuador vulneró la garantía plasmada en el artículo 8.1 de la Convención Americana en lo que respecta a la duración razonable del proceso penal.

Sobre el derecho de defensa de Montesinos Mejía, la Corte recordó lo dicho en el caso Barreto Leiva vs. Venezuela, donde expuso la centralidad e importancia que representa el derecho a la defensa para garantizar el debido proceso, defensa que ha de comenzar desde que se sindica a una persona como posible autor o partícipe de un delito hasta que finaliza el proceso, incluso en lo que respecta a la ejecución de la pena. Al considerar la declaración presumarial vertida por Montesinos Mejía en sede policial —elemento central de la condena sufrida por el delito de testaferrismo-, la Corte consideró que la falta de asistencia legal en dicha declaración vulneró los derechos contemplados en el artículo 8.2, incisos b, c y d de la Convención Americana, en perjuicio de Montesinos Mejía.

En este orden de ideas, la Corte analizó si correspondía excluir como prueba la declaración vertida por Montesinos en sede judicial en presencia de miembros del Ministerio Público Fiscal, pero no de sus defensores técnicos. Al respecto, y siguiendo la misma línea de razonamiento vista en el caso Cabrera García y Montiel Flores vs. México, la Corte consideró que generalmente las declaraciones obtenidas bajo coacción carecen de veracidad, toda vez que la persona intentará aseverar aquello que desea escuchar quien está ejerciendo coacción. Al no haber contado con la presencia de una defensa técnica, la Corte encontró responsable al Estado ecuatoriano por la violación del artículo 8.3 de la Convención Americana. 


\section{Reparaciones}

Por último, previo a emitir la parte dispositiva de la sentencia, la Corte se avocó al estudio de las reparaciones que el presente caso ofrecería. En ese sentido, como lo sostuvo en el caso Jenkins vs. Argentina, afirmó que la reparación del daño ocasionado por la infracción de una obligación internacional requiere, siempre que sea posible, la plena restitución (restitutio in integrum), que consiste en el restablecimiento de la situación anterior. De no ser esto factible, como ocurre en la mayoría de los casos de violaciones a derechos humanos, el Tribunal determina medidas para garantizar los derechos conculcados y reparar las consecuencias que las infracciones produjeron. Por tanto, la Corte ha considerado la necesidad de otorgar diversas medidas de reparación a fin de resarcir los daños de manera integral, por lo que, además de las compensaciones pecuniarias, las medidas de restitución, rehabilitación, satisfacción y garantías de no repetición tienen especial relevancia por los daños ocasionados.

En este sentido, la primera conclusión es considerar como parte lesionada a Mario Montesinos Mejía, quien, en su condición de víctima de las vulneraciones sufridas y reconocidas en la sentencia, será acreedor de lo que la Corte ordene. Luego, la Corte consideró pertinente ordenar, como medida de satisfacción y restitución, la publicación del resumen oficial de la sentencia en un periódico de amplia circulación nacional, como también la publicación de la sentencia en un sitio web oficial, de manera que pudiera acceder todo el público interesado.

En lo que respecta al delito de testaferrismo, es decir el único delito por el cual Montesinos fue condenado (recordemos que fue sobreseído por los delitos de enriquecimiento ilícito y conversión y transferencia de bienes), la Corte dispuso que el Estado debía adoptar todas las medidas pertinentes en su ordenamiento jurídico local o interno para dejar sin efecto las consecuencias de cualquier índole que se derivasen del indicado proceso penal, incluso los antecedentes judiciales, administrativos o penales que existieran en su contra producto de dicho proceso.

Como bien se adelantó, la Corte consideró que el Estado ecuatoriano incumplió con su obligación internacional de investigar los hechos de tortura, tratos crueles, inhumanos y degradantes denunciados por Montesinos. Por ende, la Corte dispuso que el Estado ecuatoriano debía iniciar la investigación necesaria a los fines de determinar, juzgar y, en su caso, condenar a los responsables de los tratos y torturas denunciadas. Como medidas de rehabilitación, la Corte dispuso que el Estado debía brindar gratuito, adecuado y efectivo tratamiento psicológico y psiquiátrico, requerido por Montesinos, e incluso la provisión de los medicamentos necesarios. Esto guarda sensata coherencia con el deber del Estado de reparar integralmente el daño frente a la imposibilidad de volver las cosas a su estado anterior. Por último, en relación con la indemnización compensatoria, la Corte discriminó lo referido al daño material del daño inmaterial. Sobre el primero de ellos, sostuvo que el Representante no presentó oportunamente prueba alguna en su escrito de solicitudes y argumentos que acreditasen el nexo causal existente entre los hechos del caso y el detrimento pecuniario. Por tanto, la Corte no ordenó una reparación material a favor de Montesinos. En lo que hace al daño inmaterial, lejos de los 500.000 dólares americanos que solicitó el Representante, la Corte reconoció como indemnización equivalente la suma de 50.000 dólares americanos. Como gastos y costas de proceso, la Corte reconoció la suma de 15.000 dólares americanos. Si bien el Representante y la Comisión solicitaron medidas adicionales, la Corte consideró que no era necesaria la imposición de medidas de reparación adicionales. 


\section{Puntos resolutivos y conclusión}

En su parte resolutiva, la sentencia de la Corte desestimó por unanimidad las cuatro excepciones preliminares interpuestas por el Estado de Ecuador.

Luego, declaró, también por unanimidad, al Estado como responsable de la violación de los derechos a la libertad personal, a la presunción de inocencia y a la protección judicial, previstos en los artículos 7.1, 7.2, 7.4, 7.5, 8.2 y 24 de la Convención Americana sobre Derechos Humanos, en relación con el artículo 1.1 de dicho instrumento, así como los artículos 7.1, 7.3 y 7.6 de la Convención Americana, en relación con los artículos 1.1 y 2 del mismo instrumento, en perjuicio de Mario Alfonso Montesinos Mejía, en los términos de los párrafos 114, 119, 128, 133 y 139 de la presente sentencia.

Por unanimidad, además, entendió que el Estado era responsable de la violación de las obligaciones de proteger y garantizar el derecho a la integridad personal, previstas en los artículos 5.1 y 5.2 de la Convención Americana sobre Derechos Humanos, en relación con el artículo 1.1 del mismo instrumento, y 1, 6 y 8 de la Convención Americana para Prevenir y Sancionar la Tortura, en perjuicio de Mario Alfonso Montesinos Mejía, en los términos de los párrafos 159 y 160 de la presente sentencia.

Por unanimidad, finalmente, el Estado era responsable de la violación del derecho a las garantías judiciales, previsto en los artículos 8.1, 8.2 b, c, d y e, y 8.3 de la Convención Americana sobre Derechos Humanos, en relación con el artículo 1.1 del mismo instrumento, en perjuicio de Mario Alfonso Montesinos Mejía, en los términos de los párrafos 188 y 195 de la presente sentencia.

Por el contrario, y también por unanimidad, el Estado no era responsable de la violación del derecho a no ser juzgado dos veces por los mismos hechos y del principio de legalidad y no retroactividad, establecidos respectivamente en los artículos 8.4 y 9 de la Convención Americana, en los términos de los párrafos 206 y 213 de la presente sentencia.

Apartado especial merece la exposición de la Corte al momento de dejar sin efecto las consecuencias de cualquier índole que se derivaran del proceso penal seguido en contra de Montesinos por el delito de testaferrismo, Mario Montesinos cargó por casi 30 años con un proceso penal y una condena sin existir elementos jurídicos que respaldaran dicha situación.

Si bien este reconocimiento de la Corte resulta esperanzador, porque establece dejar sin efecto una condena cuyo elemento ordenador es una indagatoria obtenida bajo coacción y tratos crueles, no se puede ignorar que actualmente en Latinoamérica existe una cifra preocupante de personas vulneradas en sus derechos procesales.

\section{Conclusión}

La sentencia de la Corte Interamericana de Derechos Humanos en el caso Montesinos Mejía guarda, como se puede advertir, una armónica coherencia con lo resuelto en fallos anteriores. Tal como lo sostuvo en Suárez Rosero o López Álvarez, la Corte enfatiza la necesidad de evitar detenciones arbitrarias e ilegales, junto a la importancia de la fundamentación sobre motivos suficientes al momento de analizar los parámetros o requisitos para el dictado de la medida cautelar más grave de los ordenamientos jurídicos internos: la prisión preventiva. 
Conforme a los datos oficiales del Estado de Ecuador, para 2019, la tasa de personas privadas de su libertad por el dictado del instituto de prisión preventiva ascendía al 34 por ciento (Ministerio de Justicia, Derechos Humanos y Cultos, 2019), lo que se puede interpretar expresando que un tercio de la población penitenciaria ecuatoriana encuentra vulnerado uno de los principios más elementales del derecho penal, como es la presunción de inocencia. Recordemos que la Corte expuso con claridad meridiana que el tiempo de privación de libertad sufrida por Montesinos resultó ser un adelanto de pena, o la imposición de una pena anticipada, toda vez que se acreditó la inexistencia de elementos que permitieran fundar responsablemente su prisión preventiva.

A contrario sensu de la línea argumentativa de la Corte, la gran mayoría de los ordenamientos jurídicos domésticos de los Estados Parte de la Convención son reticentes a reconocer el impacto y alcance de las sentencias de la Corte. Podemos advertir que existen Estados que, en vez de flexibilizar los criterios de peligrosidad a los fines de evitar encarcelamientos preventivos arbitrarios, incorporan nuevos requisitos para analizar si corresponde el recupero de la libertad, por caso las pericias psicológicas, lo que habla a las claras de un derecho penal de autor.

El fallo Montesinos Mejía ofrece una sólida herramienta de raigambre supranacional para que todos los Estados Parte de la Convención Americana de Derechos Humanos sean respetuosos de las garantías judiciales a los fines de asegurar el debido proceso. Cuando el encarcelamiento preventivo pasa de ser una excepción a constituir la regla, el fallo Montesinos Mejía define un camino de sensatez jurídica al reconocer a la libertad individual como uno de los pilares más sólidos en la estructura del Derecho; libertad que no puede ser limitada ni coartada por la sola alegación de un potencial peligro.

Estos pronunciamientos ponen de relieve la imperiosa necesidad de armonizar los ordenamientos jurídicos domésticos con los establecidos por la Convención, a fin de evitar procesos penales de tan larga resolución y escasa confianza en cuanto al respeto de las garantías judiciales. Arribar a dicha correspondencia evitaría, además, la necesidad de recurrir a un órgano de competencia supranacional para garantizar el celoso cumplimiento de la normativa convencional, a cuya observancia están obligados los Estados Parte. En Argentina, las estadísticas no son para nada alentadoras con relación a la población penitenciaria detenida bajo el instituto de la prisión preventiva. Según el Sistema Nacional de Estadística sobre Ejecución de la Pena para el año 2019 en la republica argentina de un total de 109.405 personas privadas de su libertad, 56.270 se encontraban condenados, mientras que 43.752 resultaban ser las personas que se encuentran con un proceso penal abierto en su contra. Esta cantidad de personas procesadas, detenidas sin condena firme, dan cuenta de la urgencia que existe de receptar y aplicar los criterios fijados por la Corte interamericana en sus sentencias para trasladar los ideales plasmados en sus decisiones a la realidad de los tribunales nacionales. 


\section{REFERENCIAS BIBLIOGRÁFICAS}

- Carranza, Elías. (2001). "Sobrepoblación penitenciaria en América Latina y el Caribe: situación y respuestas posibles". En Justicia penal y sobrepoblación penitenciaria. San José, Costa Rica: Siglo XXI.

- Corte Interamericana de Derechos Humanos. (2006). Caso Claude Reyes y otros vs. Chile.

- Corte Interamericana de Derechos Humanos. (2006). Caso López Álvarez vs. Honduras.

- Corte Interamericana de Derechos Humanos. (2008). Caso Bayarri vs. Argentina. Excepción Preliminar, Fondo, Reparaciones y Costas.

- Corte Interamericana de Derechos Humanos. (2009). Caso Anzualdo Castro vs. Perú.

- Corte Interamericana de Derechos Humanos. (2019). Caso Jenkins vs. Argentina.

- Ministerio de Justicia y Derechos Humanos, Sistema Nacional de Estadística sobre Ejecución de la Pena (2019). Disponible https://www.argentina.gob.ar/sites/default/files/informe_sneep_argentina_2019.pdf

- Ministerio de Justicia, Derechos Humanos y Cultos (Ecuador). (2019). Reporte mensual de personas privadas de libertad. Disponible en: https://www.justicia.gob.ec/reportemensual-de-personas-privadas-de-libertad/ 